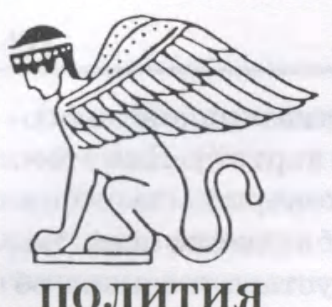

КОлития

лЕТо 1997

\title{
ГРАЖДАНСКОЕ ОБЩЕСТВО
}

А. Н. Олейник

\section{СРЕДСТВА МАССОВОЙ ИНФОРМАЦИИ И ДЕМОКРАТИЯ (ЭКОНОМИЧЕСКИЕ ПРЕДПОСЫЛКИ НЕЗАВИСИМОСТИ ЭЛЕКТРОННЫХ СМИ)*}

Лозунг свободы слова и освобождения средств массовой информации от партийного и государственного контроля играл важную роль на первых этапах демократических преобразований в России. Действительно, построение демократического общества невозможно без заполнения образовавшегося в советский период вакуума между сферами общественной и частной жизни. В начале перестройки дело осложнялось не только отсутствием промежуточных звеньев между этими двумя сферами - политических партий, социальных движений, гражданских инициатив, но и противоречием норм, лежащих в их основе. Независимые СМИ как раз и призваны облегчить процесс развития социальных и политических акторов $^{1}$, поиск консенсуса между ними.

Формирование независимых средств массовой информации - один из факторов стабильности демократического общества в целом. Способствуя самоидентификации акторов и их мобилизации, СМИ создают механизмы влияния на государство со стороны граждан. Наличие политических партий, социальных движений - лучшая гарантия против возможности повторения әкспансии государства в другие сферы общественной и част- ной жизни. Однако могут ли СМИ предотвратить или ограничить әкспансию рынка? Суть ее заключается в распространении норм рыночного поведения далеко за пределы собственно круга сделок на рынке. Например, политическая жизнь общества строится по законам политического рынка, на котором покупаются и продаются голоса избирателей, а сама политическая деятельность подчинена задаче увеличения доходов ее участников. Как писал американский политолог М. Вальцер, экономическая власть становится условием власти в политике, а неравенство в доходах условием неравенства в правах ${ }^{2}$. Именно опасность әкспансии рынка - одна из важных проблем в сегодняшней России. Ведь в результате этого окажутся под вопросом не только принципы деятельности СМИ, но и перспективы демократии в целом. Поэтому лозунг обеспечения независимости СМИ остается по-прежнему актуальным, только теперь он имеет иное содержание.

Вопрос о независимости средств массовой информации в тоталитарном государстве носит прежде всего политический характер, ведь тоталитаризм заключается в попытке построения всех сфер общественной и частной жизни по нормам и пра-

- Статья написана при поддержке Фонда Джона и Кэтрин Макартуров. Автор так же выражает благодарность за участие в финансировании пилотажного опроса руководителям радиостанций "Маяк», "Надежда", “Эхо Москвы», “М-Радио», "Престиж-радио», «Открытое радио». Особая благодарность за помощь на начальных этапах исследования обращена к И. С. Королевой, генеральному директору радиостанции «Надежда» и к. ист. наук С. В. Патрушеву (ИСП РАН).

' Актор - действующее лицо, субъект социальных и политических процессов. В статье используется термин «социологии дей. ствия», чтобы подчеркнуть активную роль партий и социальных движений в формировании и функционировании демократического общества.

${ }^{2}$ Walzer M. La justice dans les institutions. - «Esprit», vol. 180, 1992, №3-4, p. 113-114 
вилам так называемого "гражданского соглашения", в основе которого лежит безусловный приоритет общественных интересов над частными. Плох не сам указанный принцип, замечают французские социологи Л. Балтански и Л. Тевенот, губительна экспансия этого принципа на другие сферы, когда, например, даже сделки на рынке должны быть опосредованы политическими отношениями ${ }^{3}$. Наоборот, вопрос о независимости СМИ при угрозе экспансии рынка приобретает прежде всего экономическое содержание. Ведь в этом случае правила рыночных сделок переносятся и на политическую сферу, и на область деятельности СМИ. Зависимость СМИ обусловливается теперь не их встроенностью в пирамиду властных отношений, а экономической несамостоятельностью, иногда даже убыточностью прессы и әлектронных средств массовой информации.

Ситуация с телевидением и радио особенно сложна ввиду специфического характера предоставляемых ими услуг. Если газеты и журналы невозможно прочитать, не заплатив определенной суммы денег за содержащуюся в них информацию, то для доступа к программам телевидения и радио достаточно купить телевизор и радиоприемник и получить таким образом возможность неограниченно и совершенно бесплатно пользоваться услугами электронных СМИ.

Производство «общественных благ» всегда убыточно, ибо никто не хочет за них платить, несмотря на то, что все в них заинтересованы (подобная проблема на общественном транспорте решается с помощью контролеров и штрафных санкций для безбилетников). Традиционный способ решения проблемы «общественных благ" - их производство государством. Например, общественный транспорт, как правило, находится в муниципальной собственности. Участие государства в собственности теле- и радиостанций (или владение контрольным пакетом акций) также снимает с повестки дня вопрос об их финансировании. Однако даже о формальной независимости телевидения и радио в этом случае говорить не приходится. Американский әкономист Р. Коуз приводит пример действий демократически избранного Совета директоров Би-би-си перед второй мировой войной, который лишил У. Черчилля, в то время морского министра, возможности критиковать в эфире «умиротворяющую» политику британского правительства по отношению к Гитлеру ${ }^{4}$. На смену политической зависимости от государства приходит әкономическая, подчас еще более жесткая и обязывающая. В России борьба с дефицитом бюджета часто принимает форму невыполнения государством своих обязательств, невыплаты денежных средств, полагающихся государственным теле- и радиокомпаниям.

Однако предположим идеальный случай: демократическое государство полностью выполняет свои бюджетные обязательства. Демократический характер государства - гарант против использования средств массовой информации в политических целях. Наиболее вероятный способ финансирования здесь - специальный налог на владельцев теле- и радиоприемников. Такой целевой налог не создает дополнительной нагрузки на бюджет и снижает до минимума зависимость финансирования әлектронных СМИ от произвола чиновников, распределяющих бюджетные средства. Таким образом, государство фактически заставляет потребителей (зрителей и слушателей) оплачивать услуги телевидения и радио. Могут ли при такой схеме финансирования потребители влиять на качество производимой продукции? Не станут ли электронные СМИ независимыми не только от государства, но и от зрителя-слушателя?

Фиксированная ставка налога, с одной стороны, лишает зрителей и слушателей возможности выражения своих предпочтений. На одинаковое финансирование в этом случае могут рассчитывать как самые популярные станции, так и станции-аутсайдеры. Причем рейтинги популярности не могут быть использованы в качестве критерия распределения средств: рейтинги имеют иную природу, чем индексы удовлетворенности программами ${ }^{5}$. Одно дело - приобретать понравившийся товар, другое - покупать товар потому, что нельзя найти ничего лучше. Вместе с тем единая ставка налога не позволяет и максимизировать объем платежей, достигаемый при установлении для каждой категории зрителей и слушателей специальных тарифов, исходя из уровня их дохода и степени потребности в тех или иных программах ${ }^{6}$. Достаточно высокий налог .к тому же сократит аудиторию теле- и радиопрограмм, что противоречит әкономической эффективности производства «общественных благ». Поскольку каждое дополнительное использование этих благ не уменьшает их полезности для остальных потребителей, оптимальна такая плата за них, которая не исключала бы ни одного зрителя и слушателя, что возможно только при установлении дифференци-

\footnotetext{
${ }^{3}$ Boltanski L., Thevenot L. De la justification. Les economies de la grandeur. Paris, 1991, p. 142, 144

${ }^{4}$ Coase R., Barrett E. Educational TV: Who Should Pay? Wash., 1968, p. 77

${ }^{5}$ Kopp P. Television en concurrence. Paris, 1990, p. 32

${ }^{6}$ Owen B., Wildman S. Video Economics. Cambridge, 1992, p. 24, 29.
} 
рованных тарифов для каждой зрительской группы. Введение же дифференцированного налога представляется маловероятным в силу высоких издержек на сбор информации и на выделение различных групп зрителей и слушателей.

Итак, можно сделать следующий вывод: финансирование электронных СМИ посредством государства связано с опасностью экономической зависимости от политических интересов групп, контролирующих его аппарат. Даже в демократическом государстве зрители и слушатели не имеют возможности влиять на качество и разнообразие оплачиваемых из их кармана программ, то есть телевидение и радио становятся независимыми от своей аудитории.

Альтернатива государственному патернализму над әлектронными СМИ - их финансирование $c$ помощью рекламы. Ориентация на доходы от размещения рекламы, казалось бы, гарантирует экономическую и политическую независимость әлектронных СМИ от государства и не ограничивает аудиторию программ установлением фиксированной цены за возможность смотреть и слушать передачи. Так ли, однако, оптимально с точки зрения собственной логики деятельности телевидения и радио финансирование через поступления от рекламы? Первая опасность здесь связана с возможностью контроля над теле- или радиостанцией со стороны крупного рекламодателя, в роли которого чаще всего выступает рекламное агентство. Особенно эта опасность велика в отношении радиостанций, где издержки производства программ меньше, чем на телевидении, и, следовательно, выше вероятность появления единственного спонсора. Впрочем, как показывает опыт рекламного агентства «Публиталиа" и холдинга "Фининвест» С. Берлускони, которые в 80-е начале 90-х годов контролировали 90\% коммерческого телевидения в Италии (в том числе каналы Rete Quatro, Canale Cinque, Italia Uno), и на телевидении опасность контроля со стороны рекламодателя-монополиста достаточно высока.

Частично проблема контроля со стороны рекламных агентств может быть решена с помощью ограничений на участие в собственности теле- и радиокомпаний. Так, в США участвовать в капитале разрешено 12 телекомпаниям и 12 радиостанциям в диапазоне коротких волн и УКВ ${ }^{7}$, Кроме того, запрещается владеть больше, чем одной телекомпанией в регионе. Однако формальное рас- пределение прав собственности чаще всего не дает представления о реальном экономическом влиянии на политику теле- и радиостанций. Во всяком случае, корреляция между формой собственности и содержанием передач практически отсутствует $^{8}$. Напротив, связь между способом финансирования и содержанием передач существует и значима. Здесь важно не столько констатировать факт подчинения теле- или радиокомпании конкретному рекламному агентству, сколько изменение самого характера вещания в результате ориентации на поступления от рекламы.

Превращение телевидения и радио в одну из отраслей бизнеса, сферу господства рекламы подчиняет электронные СМИ логике «продажи аудиторий рекламодателям ${ }^{9}$. Подчеркнем принципиальную разницу между собственной логикой деятельности СМИ и логикой «продажи аудиторий». Последняя предполагает «борьбу за зрителя», успешная стратегия в которой сводится к учету интересов «среднего» зрителя. В результате происходит унификация программ различных компаний, как бы ни было велико их число. Наоборот, чем больше конкурирующих компаний, тем менее разнообразны их программы, обращенные к одной и той же аудитории ${ }^{10}$. Ситуация аналогична борьбе политических партий за «среднего избирателя, итогом которой становится смещение всех их к "центру" и постепенное стирание различий в политических программах. Кроме того, неверно и предположение о том, что размер аудитории при финансировании через поступления от рекламы ничем не ограничен. Ценность расширения аудитории программы еще на одного зрителя определяется дополнительным доходом, который может принести этот зритель в качестве покупателя рекламируемых товаров. Бюджет программы, а следовательно, и ее качество, напрямую зависят от рекламной ценности аудитории ${ }^{11}$. Размер аудитории определяется не важностью программ для зрителя-слушателя, а ценностью последнего для рекламодателя.

Здесь необходимо обратить внимание еще на один важный аспект в ориентации электронных СМИ на рекламу. В конечном счете, как и в случае с налогом, рекламу оплачивает зритель-слушатель в качестве потребителя рекламируемых товаров. Цена рекламы выражается для потребителя в увеличении цены рекламируемых товаров плюс неудобства, связанные с постоянным пре

\footnotetext{
${ }^{7}$ Bonnell R. La vingt-cinquieme image. Une economie de l'audiovisuel. Paris, 1989, p. 528.

${ }^{8}$ Compaine B, and Alii. Who Owns the Media? Concentration of Ownership in the Mass Communications Industry. N. Y, 1979, p. 100.

${ }^{9}$ Owen B., Wildman S., Op. cit., p. 3.

${ }^{10}$ Kopp P. Op. cit., p. 136; Owen B., Wildman S. Op. cit., p. 84.

"Kopp P. Op. cit, p. 162
} 
рыванием программ рекламными роликами ${ }^{12}$. Причем неудобства последнего рода настолько существенны, что даже в отсутствие законодательных ограничений на длительность рекламы ее объем в лучшее время на американском телевидении не превышает 7 минут в час.

Несмотря на то, что зритель-слушатель финансирует программы, у него нет возможности влиять на их содержание. Как и в случае с государством, между зрителем и телекомпанией стоит посредник - рекламная фирма. Традиционные же показатели зрительских предпочтений, рейтинги, на основе которых строятся взаимоотношения между рекламодателем и теле-, радиокомпанией, мало что могут сказать и в этом случае: они неспособны измерять интенсивность предпочтений ${ }^{13}$. Иначе говоря, финансирование через доходы от продажи аудиторий рекламодателям связано с опасностью как прямого контроля с их стороны, так и господства коммерческой, рыночной логики в программной политике әлектронных СМИ. Единственная независимость, которая при әтом достигается, - это независимость от интересов зрителей и слушателей.

На первый взгляд, совмешение государственных дотаций с доходами от рекламы может дать хороший результат. Например, в 1989 г. дотации обеспечивали $33,5 \%$ поступлений французской телекомпании «Антенн-2», а доходы от рекламы - 63\%; аналогичные цифры для телекомпании "Франс-3» составили $82 \%$ и $14 \%$. Но опыт этих компаний показывает, что комбинация двух источников финансирования - государственных дотаций и доходов от рекламы - только усугубляет дело. При смешанном финансировании складываются не преимущества, а недостатки обеих систем. С точки зрения содержания программ смешанное финансирование создает предпосылки для соседства в эфире религиозных и образовательных программ с программами откровенно развлекательного характера. При этом разрушается концепция канала или волны, возрастает их эклектичность.

Третий вариант финансирования электронных СМИ - системы платного телевидения и радио. Сегодня прямые платежи зрителей обеспечивают более одной трети доходов американского телевидения. При такой системе финансирования отсутствуют посредники между зрителями-слушателями и теле-, радиокомпаниями. В результате облегчается процедура выражения зрителями-слушателями своих предпочтений и измерения их интенсивности в денежной форме ${ }^{14}$. Обычная для ориентированных на рекламу телевидения и радио дискриминация малых и средних аудиторий преодолевается высоким платежеспособным спросом отдельных категорий на образовательные и культурные программы. Отметим, что выбор в пользу платного телевидения часто обусловлен и желанием избавиться от становящейся все назойливей рекламы: $60 \%$ абонентов платного телевидения в США указывают в качестве причины своего выбора желание радикально уменьшить количество рекламы на әкране ${ }^{15}$.

Впрочем, платному телевидению и радио присущи два существенных недостатка. Во-первых, внедрение системы связано со значительными издержками, которые на первых порах могут превышать потенциальные выгоды. Но даже и после осуществления капитальных инвестиций в кабельное оборудование и/или систему кодирования издержки остаются высокими. Так, цена просмотра одного фильма в системе платного телевидения и радио, 4-5долл., складывается на 40\% из оплаты авторских прав на фильм, на 20 - из оплаты услуг оператора, на 40 - из оплаты услуг оператора кабельной сети ${ }^{16}$. Иными словами, до $60 \%$ стоимости просмотра идет на оплату технического обеспечения.

Во-вторых, платность просмотра (прослушивания) ограничивает аудиторию. Причем в силу высокой цены, включающей техническое обеспечение, это ограничение существенно ${ }^{17}$. Напомним, что продукция телевидения и радио имеет характер «общественных благ» и любое ограничение аудитории повышает издержки в расчете на одного зрителя-слушателя. Чем ограниченнее аудитория программы, тем выше издержки ее производства, приходящиеся на отдельного зрителя-слушателя. Получается, что платное телевидение и радио снижают эффективность производства программ электронными СМИ.

Может ли быть разрешено противоречие между требованием не ограничивать аудиторию и принципом платности, который дает зрителю-слушателю возможность неопосредованной обратной связи с телевидением и радио? Проанализируем в этой перспективе четвертый вариант финансирования электронных СМИ, добровольный налог. Каждому зрителю и слушателю предлагается внести доб-

12 Sawers D. Financing for Broadcasting. In: Freedom in Broadcasting. London, 1989, p. 85.

${ }^{13}$ Brittan S. The Case for Consumer Market. Ibid., p. 29.

${ }^{14}$ Coase R., Barrett E. Op. cit., p. 70-73.

${ }_{15}$ Mariet F. La television americaine. Medias, marketing et publicite. Paris, 1992, p. 143

${ }^{16}$ Bonnell R. Ibid, p. 411.

17 Owen B., Wildman S. Op. cit., p. 114. 
ровольный взнос в пользу любимой радиостанции и телеканала. Причем этот платеж должен осуществляться с минимальными для зрителя-слушателя издержками, поэтому оптимальна так называемая система "сопроводительных платежей» . Добровольные взносы вносятся при ежемесячной оплате коммунальных услуг в отделениях банков, обслуживающих коммунальные платежи. В расчетные книжки по коммунальным услугам вклеивается дополнительная страница с предложением о выплате добровольного налога и перечнем теле- и радиостанций, в пользу которых можно сделать взнос. Таким образом, отпадает необходимость в дополнительной затрате времени на осуществление платежей, минимальны и операционные издержки в расчете на один рубль собранных средств. Как видим, выгоды по сравнению с отправкой взносов по почте или со сбором средств во время публичных акций налицо.

Добровольный налог в самых различных его формах - обязательной, возвратной (платежи осуществляются всеми, но могут быть возвращены), добровольной, широко применяется в США для финансирования потребительских организаций, избирательных кампаний, целевых исследований и различных общественных акций ${ }^{18}$. Однако наибольший интерес представляет его использование для финансирования электронных СМИ. В США каждый десятый зритель общественного телевидения делает добровольные взносы, составляющие $21,6 \%$ бюджета станций общественного телевидения ${ }^{19}$. Что касается их конкретного размера, то это в среднем 50 долл. в год на семью. Аналогичная система используется во Франции, где слушателям «Радио классик" предлагается приобрести годовой абонемент. Социологические опросы в Великобритании показывают, что $98 \%$ британцев готовы выплачивать добровольный налог в пользу Би-би-си, если будет отменен существующий сейчас обязательный налог ${ }^{20}$.

Какие преимущества у финансирования әлектронных СМИ через добровольный налог? Во-первых, аудитория программы не ограничивается, она остается доступной для всех зрителей и слушателей вне зависимости от факта оплаты. С экономической точки зрения әто означает, что издержки производства программ в расчете на одного зрителя остаются минимальными. С политической точки зрения отсутствие ограничений в доступе к электронным СМИ гарантирует реализацию права граждан на информацию. Во-вторых, добровольный налог позволяет измерять интенсивность предпочтений зрителей и слушателей, ведь именно они решают, какую именно сумму вносить ежемесячно. В отличие от социологических опросов необходимость составления "рейтинга" в денежной форме увеличивает ответственность зрителя-слушателя в выявлении своих предпочтений и оценке программ. А отсутствие посредников между әлектронными СМИ и зрителями-слушателями дает им возможность влиять на содержание и качество программ.

Укажем так же на возможность применения на основе добровольного налога оригинальной модели акционирования государственных каналов телевидения и радио. Регулярно вносящие взносы зрители и слушатели получают право голоса на выборах Наблюдательного совета теле- или радиокомпании. Так им удается избежать высоких издержек на организацию собрания «акционеров", которое $\kappa$ тому же имеет все шансы стать неуправляемым, учитывая потенциальное количество его участников.

Право голоса может быть делегировано выборщикам, хорошо известным зрителям и слушателям людям. Причем кому именно «акционер» делегирует свой голос - решает он сам. Функция выборщиков заключается в формировании Наблюдательного совета, который и будет определять стратегию развития теле- или радиокомпании. Подобная схема, например, предлагалась при разработке предложений по приватизации радиостанции «Маяк».

Обеспечивает ли применение добровольного налога независимость СМИ? Не попадают ли телеи радиокомпании в зависимость от вкусов своей аудитории, которая не всегда готова воспринимать объективную информацию и программы, заставляющие думать? Отметим, что если выбирать между зависимостью от государства, от бизнеса или от зрителей-слушателей, то выбор в пользу последних следует сделать уже на том основании, что именно они в конечном счете и оплачивают услуги электронных СМИ. Впрочем, угроза диктатуры зрителя-слушателя сильно преувеличена. Дело в том, что добровольные платежи никогда не могут обеспечить $100 \%$ потребности теле- и радиокомпаний в финансовых ресурсах. Поэтому электронные СМИ вынуждены комбинировать добровольные поступления от зрителей-слушателей с доходами от рекламы и государственными дотациями. Именно смешанное финансирование на

\footnotetext{
${ }^{18}$ Sharpless A., Gallup S. Banding Together: How Check-Offs Will Revolutionize The Consumer Movement. - Center for Study of Responsive Law, 1981, p. vi-viii.

${ }^{19}$ Mariet F. Op. cit., p. 67 , Bonnell R. Op. cit., p. 485

${ }^{20}$ Mariet F. Op. cit., p. 71.
} 
основе добровольного налога и является оптимальным с точки зрения обеспечения независимости әлектронных СМИ.

Как уже отмечалось, собранные в форме добровольных платежей средства служат своеобразным рейтингом теле- и радиостанций. Он характеризует аудиторию (в том числе и ее платежеспособный спрос) значительно лучше, чем традиционные социологические опросы. Общее количество рекламы сокращается, а остающаяся вполне может играть роль источника информации для потребителя и способствовать формированию торговых марок, являющихся дополнительной гарантией качества товаров и услуг ${ }^{21}$. Вместе с тем сумма собранных в форме добровольного налога средств может служить объективным критерием распределения государственных дотаций, ограничивая произвол государственных чиновников. Например, в США в 70-е годы использовалось следующее правило распределения государственных дотаций общественному телевидению: каждые 2,5 долл., собранных в форме добровольных платежей, давали право на получение одного доллара дотаций из федерального бюджета ${ }^{22}$. Таким образом, именно применение добровольного налога создает систему противовесов между различными источниками финансирования, обеспечивая әкономическую самостоятельность телевидения и радио.

Помимо преимуществ системы финансовых противовесов, заключающейся в обеспечении различных схем финансирования электронных СМИ равными правами на существование, смешанное финансирование выгодно и еще по одной причине. Оно создает предпосылки для «естественного отбора" среди различных схем финансирования, в результате которого выживут и займут доминирующее положение те схемы, которые в наибольшей мере соответствуют собственной логике развития СМИ. Здесь уместно привести аргумент Ф. Хайека о пользе конкуренции между различными институциональными структурами: «организуя ту или иную область жизнедеятельности, мы должны максимально опираться на спонтанные силы общества и как можно меньше прибегать к принуждению" ${ }^{23}$. Важно лишь создать равные стартовые возможности для всех четырех схем - государственного финансирования, продажи рекламного времени, платного ТВ и радио, добровольного налога. Место каждой из них определится не столько теоретическими аргументами, сколько сравнительной эффективностью в обеспечении независимости СМИ.
$* * *$

Остается ответить на один вопрос, быть может, самый важный: каковы перспективы применения добровольного налога в России? Теоретические аргументы и ссылки на западный опыт явно недостаточны для ответа на этот вопрос. Поэтому сошлемся на результаты пилотажного социологического опроса, проведенного нами в Москве в ноябре - декабре 1996 г. методом уличных интервью (выборка составила 613 человек и вопросы касались только радиостанций коротковолновых и УКВ диапазонов). Опрос проводился в различное время суток - утром $(18,4 \%$ опрошенных $)$, днем $(46,1 \%)$ и вечером $(35,5 \%)$.

Половозрастная структура выборки позволяет говорить о репрезентативности полученных результатов: мужчины составили $50,3 \%$ от общего числа опрошенных, женщины - 49,7\%. Распределение опрошенных по пяти возрастным категориям выглядит следующим образом:

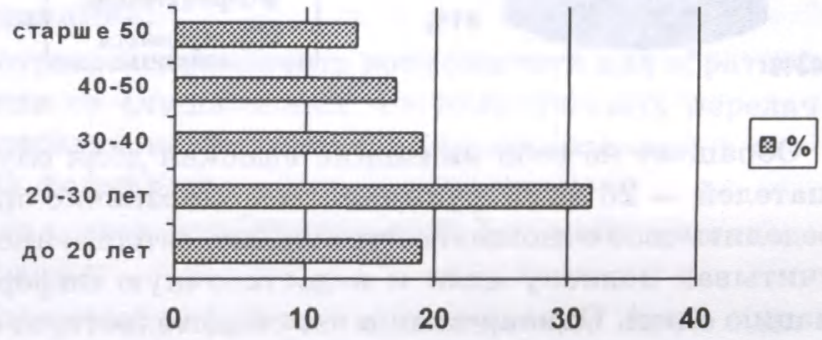

По уровню месячного дохода (в семье на одного человека) распределение получилось так же равномерным. Единственная категория, которая оказалась недостаточно представленной в выборке, это самая высокооплачиваемая (всего 14,4\% респондентов составили люди с доходам больше 1,5 млн. руб.).

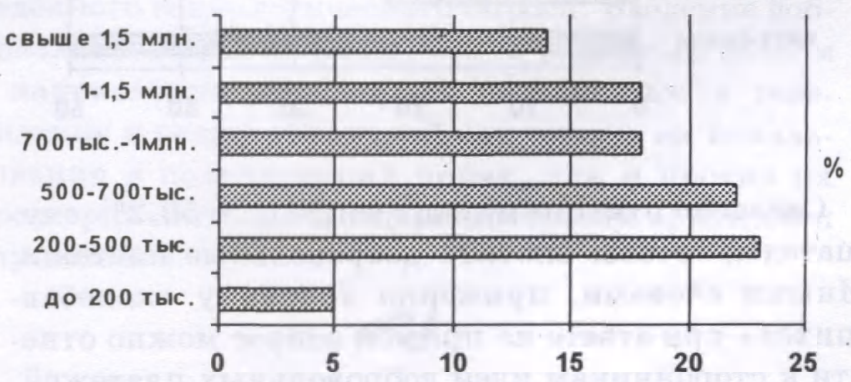

По уровню образования респондентов выборка состоит на $9,4 \%$ из людей с неполным средним

${ }^{21}$ Holcombe R., Holcombe L. The Market for Regulation. - "Journal of Institutional and Theoretical Economics", 1986, vol.142, №4, p. 688 .

${ }^{22}$ Compaine B, and Alii. Ibid., p.118.

${ }^{23}$ Хайек Ф. Дорога к рабству. М., 1992, с.21. 
образованием, на $36,5 \%$ - из имеющих среднее образование, на $17,9 \%$ - из людей с неполным высшим образованием и на $36,2 \%$ - из имеющих диплом о высшем образовании. Полученная структура выборки позволяет делать выводы о поведении самой массовой категории радиослушателей, людей со средним уровнем дохода, в возрасте от 25 до 40 лет.

Результаты анкетного опроса дают возможность оценить восприятие слушателями идеи добровольных платежей и их потенциальную готовность платить. Полученные результаты позволяют с оптимизмом смотреть на будущее системы добровольных платежей. Так, $31 \%$ респондентов положительно относятся к әтой идее:

Как бы Вы отнеслись к идее добровольных взносов в пользу любимой радиостанции? $26 \%$

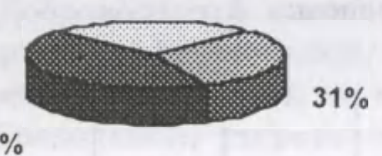

\begin{tabular}{|c|}
\hline Положительно \\
Отрицательно \\
ॠЗатрудняюсь \\
ответить
\end{tabular}

Обращает на себя внимание высокая доля слушателей $-26 \%$, затруднившихся однозначно определить свое отношение, что вполне естественно, учитывая новизну идеи и недостаточную информацию о ней. Одновременно это свидетельствует о наличии резервов в расширении числа добровольно вносящих взносы, что косвенно подтверждается ответами на вопрос о том, сколько конкретно слушатели готовы платить:

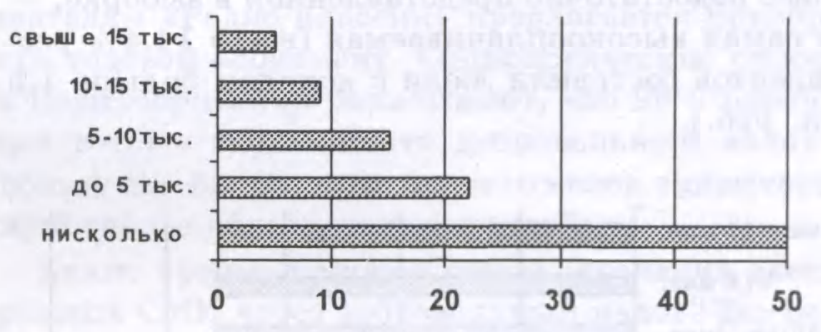

Согласно ответам на этот вопрос, до $50,2 \%$ слушателей готовы вносить добровольные платежи. Иными словами, примерно половину «колебавшихся" при ответе на прямой вопрос можно отнести к сторонникам идеи добровольных платежей. Примерно такую же величину - 53,7\% - дает ответ на вопрос "Как, по Вашему мнению, отнесутся к идее добровольных платежей другие радиослушатели?" Только $23,2 \%$ уверены, что никто не захочет платить добровольно. Более низкая личная готовность платить (31\%) по сравнению с уверенностью в активном участии других слушателей $(53,7 \%)$ подтверждает неизбежность возник- новения так называемой «проблемы безбилетника", - все заинтересованы в дополнительной поддержке радиостанций, но при этом предпочитают, чтобы платили другие. Решение этой проблемы - в совмещении механизма добровольных платежей с проведением розыгрышей денежных призов, сувениров с символикой радиостанций среди делающих взносы. Иными словами, участие в финансировании "общественного блага" стимулируется распределением «частных благ».

Следующая задача, которая ставилась перед исследованием, заключалась в определении готовности платить среди различных групп респондентов.

Во-первых, наблюдается зависимость между уровнем правовой культуры слушателя (оцененной на основании ответов на вопрос о поведении при покупке видеокассет) и его готовностью платить. Среди тех, кто стремится покупать легальные копии, большинство поддерживают идею добровольных платежей, тогда как среди не обращающих внимание на легальность копии значительно больше противников әтого механизма. Отсюда две гипотезы: первая - динамика рынка видео, точнее, его легального сегмента, может служить критерием готовности населения воспринять идею добровольных платежей. Вторая - развитие элементов рыночного сознания у российского населения будет облегчать, а не затруднять внедрение механизма добровольных платежей.

Во-вторых, наибольшее число сторонников добровольных платежей находится среди тех, кто слушает радио $2-3$ часа в день (36\% от общего числа последних). Минимальна готовность платить со стороны тех, кто слушает радио до 1 часа и 35 часов в день. Можно предположить, что те, кто слушает радио "между делом" - на работе, во время обеденного перерыва, в меньшей степени готовы платить. Этот вывод подтверждается большей долей среди сторонников идеи добровольных платежей (чем по выборке в целом) тех, кто слушает радио по дороге на работу, с работы $(+3 \%)$, после работы $(+5 \%)$ и поздно вечером $(+3 \%)$.

В-третьих, среди возрастных категорий больше всего сторонников добровольных платежей в группах 30-40 и 40-50 лет; они составляют соответственно $35,4 \%$ и $38,8 \%$ против $27,6 \%$ в группе $20-25$ лет и $20,7 \%$ в группе старше 50 лет. Очевидно, что люди старшего поколения вряд ли смогут воспринять эту идею. Что касается молодежи, то ее активное участие ограничено как финансовыми возможностями, так и процедурой внесения платежей. Среди мужчин на 5,5\% больше сторонников предлагаемого механизма $(34,2 \%$ против $27,8 \%$ среди женщин).

В-четвертых, более высокой готовностью платить отличаются две группы: с доходом 700 тыс. 
- 1 млн. руб. в месяц на человека $(39,6 \%)$ и с доходом свыше 1,5 млн. руб. (37,9\%). Как видим, отнюдь не самая высокодоходная группа может стать основой функционирования механизма добровольных платежей, но с ростом дохода увеличивается сумма, которую слушатели готовы ежемесячно вносить: среди слушателей с доходом свыше 1,5 млн. руб. 16,1\% готовы вносить ежемесячно свыше 15 тыс. руб. (против $4,7 \%$ в среднем по выборке).

В-пятых, существует прямая зависимость между оценкой объема рекламы на радио и готовностью платить. Поддержку радиостанциям готовы оказать в первую очередь те, кто находит избыточным или скорее избыточным объем рекламы на радио ( $35 \%$ и $41 \%$ соответственно). Поэтому при внедрении системы добровольных платежей следует учитывать характер этих взносов как «подразумеваемого контракта" между слушателем и радиостанцией, согласно которому слушатель платит за сокращение объема рекламы в әфире.

В-шестых, не наблюдается существенных различий в готовности платить в зависимости от уровня образования.

В-седьмых, можно говорить об особых предпочтениях слушателей, поддерживающих идею добровольных платежей. В отличие от основной массы слушателей они в меньшей мере ориентированы на конкурсы (их указывают на 1\% меньше), на информационные программы $(-3 \%)$ и на прогнозы погоды $(-2 \%)$. Напротив, у них больший интерес к тематическим передачам $(+2,5 \%)$, к работе ведущих $(+2,5 \%)$, то есть к тому, что является специфическим для радио.

Таким образом, обобщенный портрет слушателя, на котором потенциально может основываться механизм сопроводительных платежей, выглядит следующим образом. Это мужчина в возрасте 30-50 лет, со средним уровнем доходов. Он слушает радио 2-3 часа в сутки не "между делом", а ради него самого, в первую очередь ради музыки, тематических и информационных передач, получая удовольствие от работы ведущих. Он отрицательно относится к засилию рекламы в эфире и ожидает снижения ее обтема в результате своих взносов. Он уважает закон. Нныли словами, сопроводительные платежи рассматриваются слушателями не как "подачка» или «милость- ня» испытывающим затруднения радиостанция.м. Напротив, в добровольном взносе они видят своего рода "контракт", «сделку" между слушателем и радиостанцией, взаимовыгодную для обеих сторон.

\section{Слушатель:}

отказывается от возможности бесплатного получения радиопрограмм;

получает возможность довести свои предпочтения до радиостанции;

ожидает сокращения объема рекламы в эфире;

ожидает признания своего вклада, которое может принимать разные формы: от сувениров с символикой любимой радиостанции до получения права голоса при определении программной политики.

\section{Радиостанция:}

сокращает объем рекламы и отказывается от проведения политики в области добровольных платежей, которую можно определить как «сбор подаяний» ;

стремится увеличить возможности для обратной связи со слушателями: от тематических передач и передач по заявкам до акционирования в особых формах;

получает дополнительный источник финансирования;

получает новый метод контроля за своей аудиторией;

получает возможность закрепления своей аудитории, снижает у слушателей стимулы переключаться с программы на программу.

Итак, механизм введения добровольного налога требует как минимум повышенного внимания и анализа его эффективности в российских условиях. Помимо серьезных теоретических аргументов в пользу этой идеи говорят и результаты проведенного социологического опроса. Введение добровольного налога может стать реальным шагом в направлении обеспечения независимости телевидения и радио, гарантией как против их использования в политических целях, так и против их коммерциализации в ущерб интересам зрителей и слушателей. 